\title{
Seed Dispersal Potential of Asian Elephants (Elephas maximus) in Kumaragala Forest Reserve, Matale District, Sri Lanka
}

\author{
D. Chathuranga*, K.B. Ranawana, C.S. Wijesundara, D. Jayasinghe \\ Department of Zoology, University of Peradeniya, Sri Lanka \\ *dilanchathuranga9@gmail.com
}

\begin{abstract}
Elephant foraging directly affects the growth, survival and vegetation dynamics of forests. They consume a variety of plants including trees, vines, shrubs and herbs. Even though elephants are considered as important seed dispersal agents, very few studies have been carried out to study the seed dispersal ability of elephants in Sri Lanka. Hence, this study was conducted in a natural forest and a bordering chena cultivation area in Maragamuwa $\left(70^{\circ} 70^{\prime} \mathrm{N}\right.$ and $\left.80^{\circ} 65^{\prime} \mathrm{E}\right)$, within Kumaragala Forest Reserve, from September 2014 to February 2015 to determine the seed dispersal capability of elephants. Three boli were collected randomly from each dung pile and rest were kept in the field and observed until the decomposition was complete. Collected boli were broken and visible seeds were identified by comparing with a reference seed collection. Unidentified seeds were cultivated in sterilised soil. Broken boli were kept in a greenhouse and watered to identify the plants whose seeds were invisible to the naked eye.
\end{abstract}

The study found a total of 84 dung piles and 252 boli were collected from those piles. Fifty three piles out of $84(63.09 \%)$ contained seeds or seedlings of one or more plant species. A total of 22 plant species belonging to nine families were observed to germinate from boli. Among these 22 species, 12 species were cultivated (representing $54.55 \%$ of the plant species germinated from boli) and $10(45.45 \%)$ were non-cultivated plant species. Seventeen plant species from chena cultivation area and six species from natural forest were found. Careya arborea and Megathyrsus maximus were the most frequently found seeds and seedlings. Among the cultivated plants, climbers (41.67\%), shrubs $(8.33 \%)$, and herbs $(50 \%)$ were found, and among the non-cultivated plants trees $(60.00 \%)$, herbs $(4.55 \%)$ and shrubs (13.64\%) were found regularly. It is interesting to note that herbs formed $50 \%$ of the cultivated plants, while they formed only $4.55 \%$ of the non-cultivated plants germinating from elephant dung boli. The results from this study could be used to develop habitat enrichment programs for wild elephants that help in mitigating the human-elephant conflict, which is now becoming a serious conservation issue for the Sri Lankan elephant.

Keywords: Mega-herbivores, Foraging, Elephant dung, Human-elephant conflict, Conservation 